\title{
Stabilized Micelles of Amphoteric Polyurethane Formed by Thermoresponsive Micellization in $\mathrm{HCl}$ Aqueous Solution
}

\author{
Yong Qiao, ${ }^{\dagger}$ Shifeng Zhang, ${ }^{\star}$ Ouya Lin,${ }^{\star}$ Liandong Deng, ${ }^{\ddagger}$ and Anjie Dong ${ }^{*} \star \star$ \\ School of Material Science and Technology, and School of Chemical Engineering and Technology, \\ Tianjin University, Tianjin 300072, China.
}

Table S-1. Elemental analysis result

\begin{tabular}{ccc}
\hline Element & Theoretical value (\%) & Measured value (\%) \\
\hline $\mathrm{C}$ & 60.59 & 59.91 \\
$\mathrm{H}$ & 9.17 & 8.90 \\
$\mathrm{~N}$ & 6.47 & 6.53 \\
\hline
\end{tabular}

The elemental analysis result conforms to the theoretical data calculated according to amounts of DAP and DMPA used in the preparation as shown in Table 1, which further confirm our analysis on polymer composition.

*To whom correspondence should be addressed. Email: ajdong@tju.edu.cn, Fax: 86-22-27890710, Tel: 86-22-27890706.

${ }^{\dagger}$ School of Material Science and Technology

\$School of Chemical Engineering and Technology 


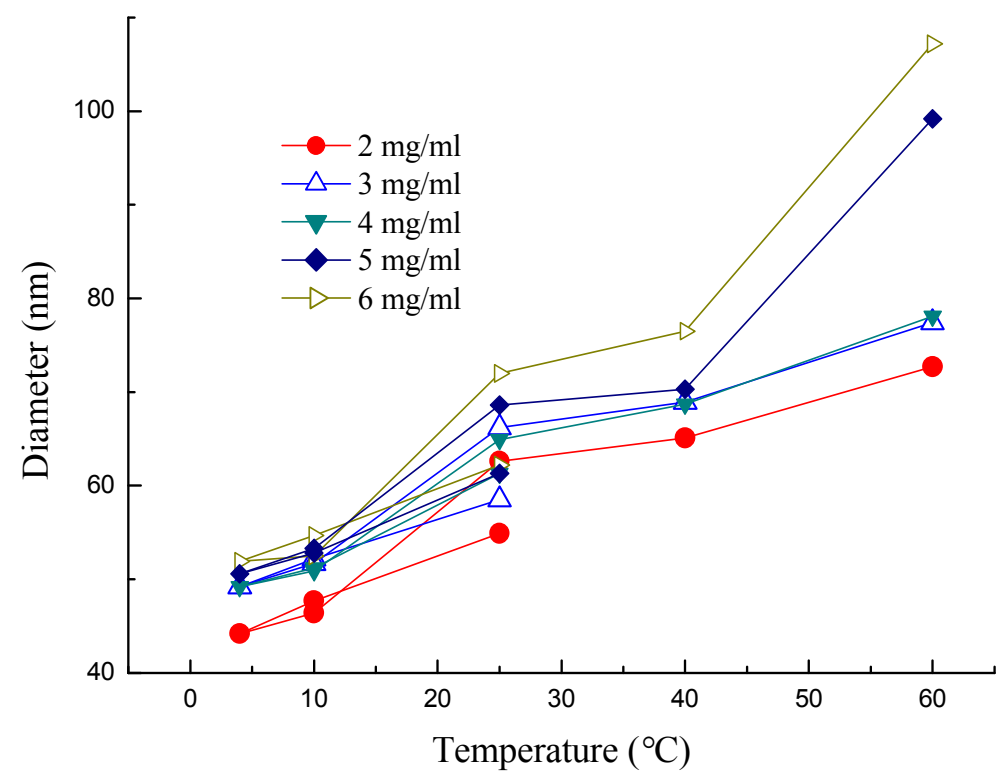

Figure S-1. $D_{\mathrm{h}}$ of $\mathrm{APU}_{(\mathrm{PTMG})}$ in $\mathrm{HCl}(\mathrm{pH} 2)$ solutions with different temperature. The temperatures are all from $25^{\circ} \mathrm{C}$ to 4 and then to 60 .

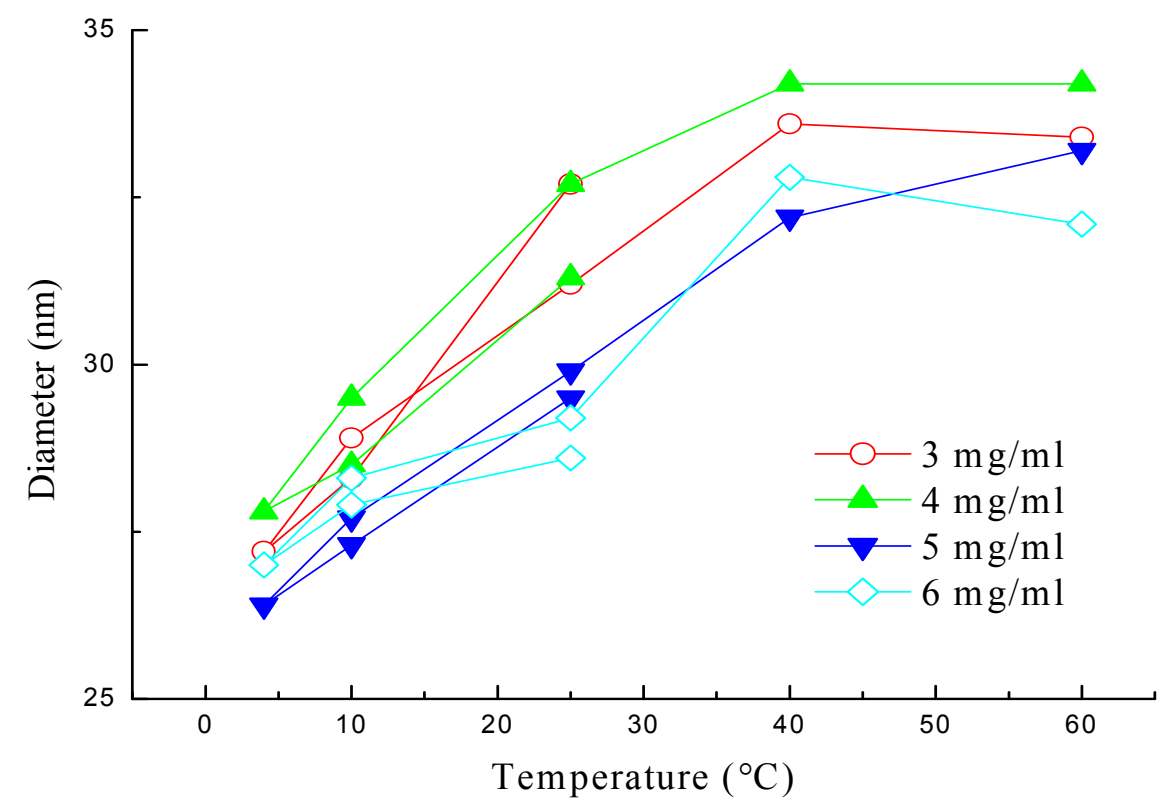

Figure S-2. $D_{\mathrm{h}}$ of $\mathrm{APU}_{(\mathrm{PCL})}$ in $\mathrm{HCl}(\mathrm{pH} 2)$ solutions with different temperature. The temperatures are all from $25^{\circ} \mathrm{C}$ to 4 and then to 60 . 

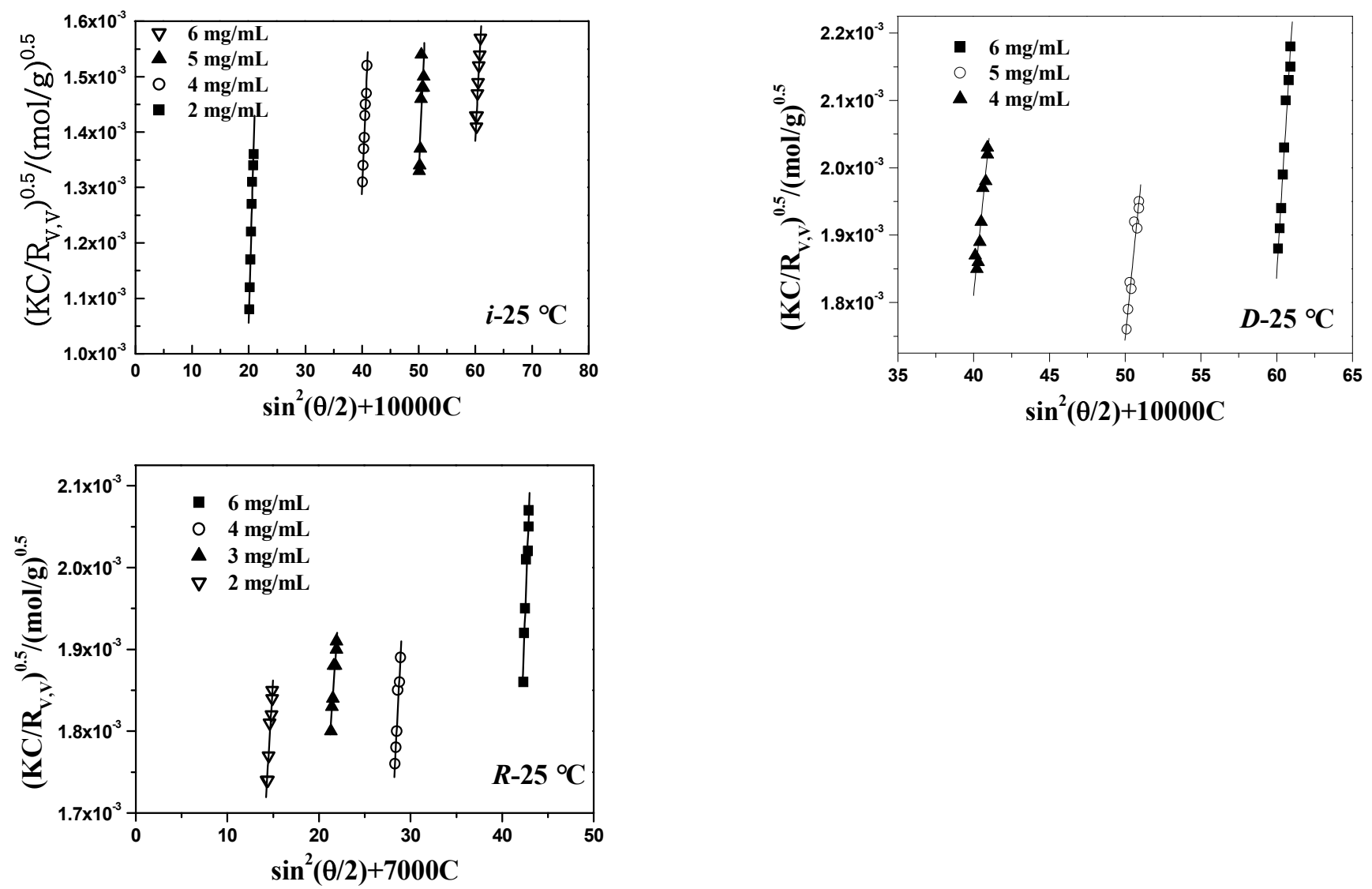

Figure S-3. Typical Berry plots of APU $\left(\mathrm{A} 4_{1 / 1}\right)$ micelles at different temperature, The prefix letter ' $i$ ', ' $D$ ' and ' $R$ ' before the temperature present initial, decreasing from initial $25{ }^{\circ} \mathrm{C}$ and increasing from 4 ${ }^{\circ} \mathrm{C}$, respectively. 

ERROR: invalidrestore

OFFENDING COMMAND: - -restore--

STACK :

- savelevel -

4211

( $\mathrm{s})$

( $\mathrm{s})$

4210

( $r)$

( $r)$

4209

( $\mathrm{q})$

( q)

4208

( $\mathrm{p})$

( $\mathrm{p})$

4207

( 0 )

( o)

4206

( $\mathrm{n})$

( $\mathrm{n}$ )

4205

( $\mathrm{m}$ )

( $\mathrm{m}$ )

4204

( 1)

( 1)

4203

( k)

( $\mathrm{k}$ )

4202

( j)

( j)

4201

(i)

(i)

4200

( h)

( h)

4199

( $g$ )

( $g$ )

4198

( $f$ )

( f)

4197

( e)

( e)

4196

(d)

(d)

4195

( C)

( C)

4194

( b)

( b)

4193

(a)

(a)

4192

(')

(')

4191

$(-)$

$41 \overline{9} 0$

( $\wedge)$

$(\wedge)$ 